\title{
Ciência, telégrafos e geografia: os engenheiros militares da Comissão Rondon, 1907-1915*
}

\author{
Science, telegraphs, and geography: military engineers \\ in the Rondon Commission, 1907-1915
}

\section{Patrícia M. Aranha}

Mestre pelo Programa de Pós-graduação em História das Ciências e da Saúde, Casa de Oswaldo Cruz/Fiocruz.

Av. Brasil, 4365

21045-900 - Rio de Janeiro - RJ - Brasil

aranha2909@hotmail.com

\begin{abstract}
ARANHA, Patrícia M. Ciência, telégrafos e geografia: os engenheiros militares da Comissão Rondon, 1907-1915. História, Ciências, Saúde Manguinhos, Rio de Janeiro, v.20, n.1, jan.-mar. 2013, p.307-315.
\end{abstract}

Resumo

Tem como objeto os trabalhos de demarcação de fronteiras e inventário do território noroeste do país entre 1907 e 1915, ocasião em que se destacam as realizações da Comissão Construtora de Linhas Telegráficas Estratégicas do Mato Grosso ao Amazonas, organizada pelos ministérios da Guerra, Viação e Obras Públicas e Agricultura, com vistas à integração nacional. A pesquisa tem por finalidade apresentar as formas pelas quais se desenvolviam os trabalhos de levantamento topográfico, realizados pelos engenheiros militares enviados pelo Ministério da Guerra, e compreender as atividades desses militares em campo. Além disso, há interesse nas demandas do Ministério da Guerra e em como o atendimento a elas se dava no interior da comissão.

Palavras-chave: comissão Rondon; ciência; engenheiros militares; geografia; território.

\section{Abstract}

The article focuses on the work to demarcate borders and chart the Brazilian northwest from 1907 to 1915, a project aimed at national integration and undertaken by the Rondon Commission for the Construction of Telegraph Lines from Mato Grosso to Amazonas, which was organized by the Brazilian ministries of War, Transportation and Public Works, and Agriculture. The study explores the ways in which topographic surveys were conducted by the military engineers sent by the Ministry of War and also endeavors to understand their activities in the field. Of further interest are the demands made by the War Ministry and how they were responded to within the commission.

Keywords: Rondon Commission; science; military engineers; geography; territory. 
$\mathrm{E}$ ste texto aborda questões referentes a minha pesquisa de pós-graduação com vistas ao título de mestre no Programa de Pós-graduação em História das Ciências e da Saúde (PPGHCS) da Casa de Oswaldo Cruz, Fiocruz. Gostaria de destacar que apresento aqui as ideias principais, a partir de meu contato com as fontes.

Meu objeto se constitui no estudo dos trabalhos de exploração territorial e inventário da região noroeste do país realizados pela Comissão de Linhas Telegráficas Estratégicas do Mato Grosso ao Amazonas (CLTEMTA). Entre as questões importantes para esse estudo estão as formas pelas quais se desenvolviam os trabalhos de levantamento topográfico do território por meio da atuação dos engenheiros militares enviados pelo Ministério da Guerra e os modos como esses homens realizavam seu trabalho em campo.

\section{O cenário político-social brasileiro e a origem da Comissão de Linhas Telegráficas Estratégicas do Mato Grosso ao Amazonas}

A Comissão Rondon iniciou seus trabalhos em 1907. Nessa época, uma das questões de maior importância para o Estado brasileiro relacionava-se à integração e ao conhecimento do território, suas riquezas e sua população. Além do conhecimento dos espaços tidos como afastados da então capital federal, o Rio de Janeiro, outra questão relevante era a defesa contra possíveis investidas estrangeiras (Maciel, 1998).

Dessa forma, podemos notar o próprio Estado afirmando seu poder político após a proclamação da República. Diante da importância que o território possui, assumi-lo, conhecêlo e integrá-lo era antes de tudo um dever do Estado. Assim, podemos perceber que o exercício do poder sobre um território e seus objetos é uma das condições fundamentais para o surgimento e o estabelecimento do modelo de Estado tal como o conhecemos (Ribeiro, 2005).

Além disso, também é necessário destacar que, com o fim do Império, alguns antagonismos se estabeleceram muito fortemente na sociedade, sendo quase impossível pensar nesse período sem os levar em consideração. Um deles se baseava na ideia de que o Império representava o atraso, um símbolo pungente da centralização, enquanto a República dava conta dos anseios da população com a agilidade que a descentralização federativa propiciava (Maciel, 1998; Menezes, 2006).

Outro exemplo desse tipo de pensamento antagônico era a ideia do distanciamento entre as realidades do interior e do litoral. A imagem de um litoral modernizado e europeizado em oposição a um interior como símbolo do atraso e da doença se destacava no início do século XX. Contudo, o novo modelo de governo não desprezaria o potencial produtivo de seu território; pelo contrário, se preocuparia em protegê-lo, integrá-lo e ocupá-lo (Bigio, 2000; Maciel, 1998).

As imensas dificuldades de transporte e comunicação quando de alguns acontecimentos importantes, tais como a Guerra do Paraguai ${ }^{1}$, nos quais a visão estratégica e de controle por parte dos governantes era essencial, mostraram à população o quanto esses serviços eram precários em alguns pontos do território, comprovando a urgente necessidade de institucionalização de limites e o incentivo para a ocupação e o povoamento das regiões ao noroeste (Maciel, 1998). 
Com o debate acerca da temática da integração nacional ganhando força nos primeiros anos da República, a incorporação desses territórios tidos como isolados era um grande lema do governo federal. Dessa forma, Mato Grosso, Goiás e Amazonas se constituíam nos principais alvos do novo regime como áreas a serem integradas. À época existiam poucos caminhos terrestres que interligassem essas regiões à capital; além disso, eles eram penosos e pouco transitáveis em certas épocas do ano, como nas cheias de rios, entre os meses de dezembro e maio, por exemplo. Para chegar a tais locais, a forma comumente utilizada era fazer um longo percurso fluvial, atravessando outros países, como a Argentina, Uruguai e Paraguai, para então chegar ao Mato Grosso (Sá, Sá, Lima, 2008; Diacon, 2006; Maciel, 1998).

Para incorporação efetiva e defesa dessas regiões, parecia premente o conhecimento dessa parte do território nacional. A partir dessa discussão, um projeto político de integração territorial começou a ser pensado. Foram organizadas várias viagens científicas e comissões de exploração pelo próprio Estado brasileiro. Entre essas iniciativas do Estado estão as viagens do Instituto Oswaldo Cruz (realizadas nas duas primeiras décadas do século XX), a Comissão Construtora de Linhas Telegráficas de Goiás a Mato Grosso - Comissão de Goiás (1891/1898), a Comissão Construtora de Linhas Telegráficas do Mato Grosso - Comissão do Mato Grosso (1900/1906) e, a campanha de Rondon na Comissão de Linhas Telegráficas Estratégicas do Mato Grosso ao Amazonas - (1907-1915), por exemplo.

Muito embora os inventos técnicos - entre eles o telégrafo - fossem entendidos pelos homens de ciência e política como precursores da civilização, do desenvolvimento material do território, da integração e da promoção de uma cultura nacional, no que refere especificamente às comissões construtoras de linhas telegráficas, a preocupação do Estado brasileiro não se resumia a estabelecer as comunicações com os territórios ao noroeste do país, mas "encerrar os principais pontos do país, de forma a permitir a integração e vigilância" (Sá, Sá, Lima, 2008, p.782).

Assim, em 1891, foi criada a Comissão Construtora da Linha Telegráfica de Mato Grosso a Goiás. Essa comissão foi liderada pelo major Antônio Ernesto Gomes Carneiro e estendeu seus trabalhos até 1898. Entre 1900 e 1906, operou a Comissão do Mato Grosso, cujo objetivo era a construção de uma linha telegráfica entre Cuiabá e Corumbá (Sá, Sá, Lima, 2008; Diacon, 2006; Maciel, 1998; Bigio, 2000).

As comissões de Goiás e do Mato Grosso tinham como principal objetivo o estabelecimento de comunicações com áreas isoladas da fronteira com a Bolívia e o Paraguai. Visavam ligar as linhas já existentes em São Paulo, Minas Gerais e Rio de Janeiro a esses dois estados (Sá, Sá, Lima, 2008; Maciel, 1998).

Essas comissões estavam subordinadas, concomitantemente, ao Ministério da Guerra e ao Ministério da Viação. O Ministério da Guerra fornecia-lhes oficiais do setor de engenharia e construção do Exército, além de recrutar dezenas de praças que seriam designados para o trabalho pesado de construção de postes telegráficos e derrubada das matas (Sá, Sá, Lima, 2008).

As comissões telegráficas eram de caráter provisório, visto que eram montadas com objetivos específicos. Contudo, a Comissão de Mato Grosso teve grande relevo à época, com destaque para a atuação de Cândido Mariano da Silva Rondon na condução dos trabalhos. Dessa forma, a Comissão do Mato Grosso deu origem a outra, a Comissão de Linhas Telegráficas 
Estratégicas do Mato Grosso ao Amazonas (CLTEMTA), a comumente conhecida Comissão Rondon, que realizou seus trabalhos de 1907 a 1915.

De acordo com o próprio decreto governamental que a criou, a CLTEMTA tinha objetivos muito mais audaciosos que a anterior: destaca-se como parte de um grande plano republicano de demarcação, proteção, ocupação e povoamento das áreas que eram então entendidas como a última fronteira do Brasil (Sá, Sá, Lima, 2008). Também estavam ligados à resolução dos impasses acerca da vulnerabilidade da fronteira noroeste do país ante a investida de contingentes populacionais provenientes de países vizinhos, principalmente Bolívia e Peru, resolvendo assim questões ligadas ao trânsito indesejado de populações na zona de fronteira brasileira.

\section{Características e objetivos da Comissão de Linhas Telegráficas Estratégicas do Mato Grosso ao Amazonas: a comissão e seu papel no fomento da ciência nacional}

Em março de 1907 iniciaram-se as diferentes viagens de exploração para levantamento e reconhecimento das regiões em que seriam construídas as linhas telegráficas. As condições de trabalho da comissão eram duríssimas: longas horas de trabalho sob sol ou chuva, metas e prazos que, em campo, se mostravam muito difíceis de ser cumpridos, falta de suprimentos e de proteção para o corpo - como sapatos, por exemplo -, além das dificuldades da vida na selva e das doenças. Todas essas características convergiam em uma altíssima taxa de mortalidade. Algumas incursões, aliás, precisaram ser paralisadas devido ao grande número de baixas; um exemplo é a expedição de 1908 ao rio Juruena (Diacon, 2006; Caser, 2009).

Por conta disso, o número de deserções era muito grande. A comissão recebia toda sorte de trabalhadores, desde presos comuns aos tidos então como 'desordeiros, desocupados', além dos habituais praças, o que certamente dificultava o duro trabalho de construção da linha (Diacon, 2006). Devido às pesadas condições de trabalho e às péssimas, e frequentemente nulas, garantias de salubridade, a comissão era considerada um castigo, uma espécie de 'período de aprendizado' para os 'malfeitores e desordeiros' (Diacon, 2006). Somem-se a isso ainda fatores como falta de mão de obra necessária para os trabalhos, dificuldade em arregimentar trabalhadores e em efetuar seu transporte aos locais de trabalho, problemas de adaptação e alta incidência de doenças, como a malária, por exemplo. Nesse panorama, até mesmo os índios daquelas regiões serviram como mão de obra (Bigio, 2000).

Como já ressaltado, a CLTEMTA foi um inovador projeto nacional que uniu profissionais de diferentes áreas do conhecimento sob um empreendimento que visava não somente facilitar a comunicação por meio do telégrafo, mas conhecer, proteger e explorar os recursos naturais e humanos de regiões do Brasil tidas como desconhecidas.

À discussão acerca do valor estratégico da comissão acrescenta-se outro aspecto das atividades da CLTEMTA: os levantamentos científicos dos recursos naturais das regiões percorridas (Sá, Sá, Lima, 2008). Meu trabalho trata justamente da importância desses levantamentos - e de sua publicação em relatórios, mapas, croquis e fotografias - para a ciência nacional, além de pretender demonstrar sua relação com os objetivos republicanos modernizadores e integradores do território. É sobre esse tema que me detenho agora para melhor apresentar a pesquisa desenvolvida em meu mestrado. 
A CLTEMTA estava subordinada, concomitantemente, a três ministérios: da Guerra, da Agricultura e da Viação e Obras Públicas. E é exatamente devido a essa tripla filiação e a seu caráter misto, civil e militar, que seus objetivos foram tão diversos (Sá, Sá, Lima, 2008). O Ministério da Agricultura almejava o conhecimento de novas áreas disponíveis para a lavoura ou que pudessem ser destinadas a pastagens de gado. Já o Ministério da Viação e Obras Públicas tinha interesse na comunicação via telégrafo e na construção de estradas de rodagem que acompanhariam as linhas, também no conhecimento de rios com objetivos ligados ao transporte, ao uso dos rios como caminhos, estradas (Sá, Sá, Lima, 2008).

O Ministério da Guerra, conforme anteriormente mencionado, fornecia os oficiais engenheiros formados nas escolas do Exército - Escola Militar do Brasil e Escola de Artilharia e Engenharia, além de praças que se dedicariam ao trabalho mais pesado de construção de linhas telegráficas, como a abertura de piques na mata e a confecção dos postes. Esse ministério almejava o conhecimento da natureza e do território em si; conhecimento que se dava por meio da confecção de mapas e da ratificação e correção de mapas já existentes, alimentando, assim, de informações o Escritório Central da Comissão², bem como o próprio Ministério da Guerra. Mais uma vez destaco que o trabalho da comissão tinha por objetivo viabilizar a ocupação efetiva de espaços afastados da capital.

A Rondon e seus subordinados era delegada a tarefa de enviar a esses ministérios relatórios detalhados acerca da exploração das áreas e do andamento da execução das linhas e abertura de estradas. Esses relatórios tinham por objetivo o esclarecimento acerca do território explorado, como uma espécie de inventário (Sá, Sá, Lima, 2008; Maciel, 1998).

A comissão se destacou também por seu papel como colaboradora para a ciência nacional, pois uniu de maneira indissociável as atividades de construção do telégrafo a atividades científicas. A ela se incorporaram cientistas de instituições renomadas, entre elas o Museu Nacional e o Jardim Botânico (Sá, Sá, Lima, 2008). Os naturalistas tinham por objetivo estudar os solos para o estabelecimento de centros agrícolas, novas espécies de plantas que se adaptariam à agricultura e ao mercado nacionais, assim como a fauna e a flora das regiões por onde a comissão passava, coletando e identificando grande quantidade de espécimes até então desconhecidos pela ciência (Sá, Sá, Lima, 2008).

O material coletado durante os anos de funcionamento da CLTEMTA pelos pesquisadores e coletores, bem como por tenentes da comissão e pelo próprio Rondon, foi reunido no Museu Nacional, tendo sido estudado por profissionais da instituição e do exterior (Sá, Sá, Lima, 2008).

Uma das atividades de cunho científico da comissão que merece destaque é a demarcação de fronteiras. À comissão é creditada a demarcação de toda a fronteira oeste do Brasil (Maciel, 1998), o estabelecimento de marcos e tentativas de povoamento de determinados pontos dessa região. O trabalho de demarcação de fronteiras, levantamentos topográficos e inventários territoriais era majoritariamente executado por profissionais engenheiros do Exército (Lima, Sá, 2011).

O trabalho dos engenheiros do Exército que, subordinados ao Ministério da Guerra, realizavam levantamento topográfico e demarcação de fronteiras parece-me especialmente ilustrativo do argumento que desenvolvo na minha pesquisa de mestrado: as questões relacionadas especificamente à proteção e à ocupação do território acabaram por englobar as atividades que diziam respeito à ciência no âmbito da comissão. 
Há pouco tempo foi feito um estudo tratando do papel da comissão como colaboradora para a ciência nacional, classificando-a como uma instituição científica (Sá, Sá, Lima, 2008). Nessa pesquisa, ganham destaque como objeto os levantamentos científicos dos recursos naturais, bem como a importância desses levantamentos - e de sua publicação em relatórios - para a ciência nacional. Percebemos o quanto tais objetivos científicos da comissão estavam ligados a aspectos de estabelecimento de infraestrutura por meio do telégrafo. Assim, a CLTEMTA consiste em uma iniciativa calcada em diferentes bases e que atendia a objetivos modernizadores e integradores dessas áreas do país.

Considero igualmente a comissão uma instituição científica; contudo, os trabalhos científicos que constituem o objeto deste estudo são os de levantamento topográfico, demarcação de fronteiras, correção de mapas, levantamento de rios e seus afluentes realizados não por naturalistas de respeitados ambientes científicos, mas por engenheiros militares do Exército.

Penso que há aí uma lacuna sobre o estudo das atividades realizadas no âmbito da comissão, visto que o grupo de engenheiros subordinados à CLTEMTA e seu trabalho científico nunca foram objeto de pesquisa. A partir dessa análise, selecionei como tema de minha pesquisa de mestrado o estudo desse projeto modernizador republicano - a CLTEMTA -, que uniu de maneira indissociável a incorporação do território, por meio dos telégrafos, às atividades de exploração científica.

Pela leitura de documentos como relatórios do Ministério da Guerra, relatórios da Comissão Rondon, cadernetas com anotações de campo realizadas por engenheiros militares do Exército e mapas, considero de que forma esse trabalho era estabelecido e executado por tais profissionais enviados pelo Ministério da Guerra, bem como a maneira pela qual seus resultados eram transmitidos ao ministério. Além disso, volto-me para compreender detalhes e particularidades da formação desses engenheiros militares, bem como qual era a atuação desse grupo no interior da CLTEMTA e a maneira pela qual eram executados seus trabalhos.

Assim, meus questionamentos se localizam exatamente no 'entroncamento' dos diferentes objetivos da CLTEMTA. Melhor dizendo, se a comissão era um empreendimento que aliava de maneira indissociável o trabalho de estabelecimento da comunicação via telégrafo aos trabalhos científicos, o grupo símbolo dessa indissociabilidade era o dos engenheiros militares.

Esses profissionais eram polivalentes, estavam no limiar entre a ciência e a técnica; da mesma forma que podiam analisar onde seria colocado um poste telegráfico também estavam capacitados a e incumbidos de realizar um extenso trabalho de levantamento geográfico. Dessa forma, ressalto nessa pesquisa o trabalho desses homens no que diz respeito ao levantamento de rios e áreas a eles próximas com objetivo de estabelecer representações cartográficas desses espaços, além de ratificar ou corrigir mapas.

Os engenheiros militares da CLTEMTA eram os protagonistas da aliança entre obras públicas e conhecimento científico na ocasião. O grupo se constituía no "principal depositário do saber geográfico" do Exército. ${ }^{3}$

O saber geográfico desses engenheiros militares os habilitava tanto à defesa externa (papel tradicional do Exército) quanto à execução de trabalhos com vistas à melhoria da infraestrutura do país (Nunes, 1999). 
Reafirmo que o trabalho desses engenheiros estava concomitantemente alinhado em dois eixos: as construções com vistas à funcionalidade, circulação, ocupação, valorização e exploração do território ${ }^{4}$, e o desenvolvimento de atividades científicas que tinham por objetivo o conhecimento do território nacional. Eles eram os encarregados da confecção e correção de mapas, do levantamento de rios e seus afluentes, do levantamento topográfico e da demarcação de fronteiras. Compreender as formas e circunstâncias nas quais essas atividades foram realizadas no âmbito da Comissão Rondon é a principal questão de pesquisa do meu mestrado.

\section{O trabalho com fontes de diferentes formatos e suas inter-relações}

As fontes por mim estudadas são relatórios anuais do Ministério da Guerra de 1907 a 1915; cadernetas de campo da comissão datadas de 1907 a 1915; relatórios dos engenheiros militares com os resultados dos trabalhos da CLTEMTA de 1907 a 1915; documentos relativos à carreira militar dos engenheiros que acompanhavam a comissão e mapas feitos a partir de informações coligidas por engenheiros da comissão entre 1907 e 1915. Os relatórios anuais do Ministério da Guerra estão disponíveis online ${ }^{5}$; os relatórios da CLTEMTA por mim analisados encontram-se na biblioteca do Museu do Índio do Rio de Janeiro; os documentos com relação à carreira dos engenheiros estão depositados no Arquivo Histórico do Exército, no Palácio Duque de Caxias; e as cadernetas de campo estão arquivadas no Museu do Exército e Forte de Copacabana.

Pelos relatórios anuais do Ministério da Guerra, analiso como eram as designações desse órgão à comissão, qual trabalho era delegado aos engenheiros e como deveria ser executado. Por meio das cadernetas, intento perceber como era realizado o trabalho no campo, qual era a rotina científica dos engenheiros em serviço. Por meio da leitura dos relatórios e mapas da CLTEMTA, busco entender como o trabalho descrito nas cadernetas originou publicações detalhadas do trabalho da comissão. Com a análise dos documentos referentes à carreira dos engenheiros pretendo responder a questões referentes à formação que os habilitava a atuar na comissão enquanto produtores de ciência, bem como se houve continuidade desse tipo de serviço e/ou a divulgação de seus trabalhos durante suas trajetórias profissionais.

Para efetuar tal consideração, minha metodologia consiste em analisar quais cadernetas deram origem a relatórios publicados ou mapas realizados, para, a partir de então, verificar como era o processo, desde a coleta de informações até a publicação de relatório.

\section{Considerações finais}

Mesmo antes de finalizar toda a pesquisa, penso ser possível afirmar que, pela leitura de relatórios, mapas e cadernetas de campo, o trabalho dos engenheiros subordinados à CLTEMTA estava diretamente ligado ao reconhecimento e exploração estratégica do território brasileiro, sobretudo por meio da análise de rios como caminhos, como vias que permitiriam a penetração e ocupação dos espaços ao norte do país. Essa análise de rios consistia em estudos acerca de sua navegabilidade, sua localização, geologia, estudo da vegetação de seu entorno, de seu leito, de populações de seus arredores e de suas atividades econômicas. A partir da coleta 
de tais informações, era então possível definir a viabilidade da ocupação desses territórios. O principal produto desses estudos são os mapas das regiões, feitos a partir das anotações contidas nas cadernetas de campo.

Desse modo, a partir da pesquisa com as fontes, tenho conseguido elucidar grande parte de minhas questões quando do início do estudo. Como passo seguinte, pretendo analisar, conforme já ressaltei, como as demandas do Ministério da Guerra eram atendidas por meio da análise dos relatórios ministeriais, relacionando-os com os relatórios da CLTMTA e cadernetas. Assim, considero como as anotações de campo presentes nas cadernetas eram remetidas ao Escritório Central da Comissão e, posteriormente, ao Ministério da Guerra.

Para concluir, em relação aos engenheiros que estiveram subordinados à CLTEMTA, desenvolvo a pesquisa de informações acerca de seu perfil profissional no Arquivo Histórico do Exército para, a partir desse ponto, identificar elementos de sua instrumentalização que os qualificavam para o trabalho científico e de infraestrutura. Com base na documentação descrita, seleciono um engenheiro como personagem arquétipo de todo o grupo para, através dele, elucidar minhas questões no que tange a sua formação e seu trabalho em campo.

\section{NOTAS}

* Essa pesquisa foi defendida como dissertação de mestrado no Programa de Pós-graduação em História das Ciências e da Saúde na Casa de Oswaldo Cruz/Fiocruz, em 2011, com o título de "O esquadrinhamento do Noroeste do Brasil: o saber geográfico e os engenheiros militares da Comissão Rondon (1907-1915)", sob orientação de Dominichi Miranda de Sá.

${ }^{1}$ A Guerra do Paraguai foi o maior conflito armado internacional ocorrido na América do Sul. Foi travada entre o Paraguai e a Tríplice Aliança, composta por Brasil, Argentina e Uruguai. Estendeu-se de dezembro de 1864 a março de 1870. É também chamada Guerra da Tríplice Aliança, na Argentina e no Uruguai, e de Guerra Grande, no Paraguai. O conflito iniciou-se com a invasão da província brasileira de Mato Grosso pelo Exército do Paraguai, sob ordens do presidente Francisco Solano López, e terminou com a derrota do Paraguai para a Tríplice Aliança.

${ }^{2}$ Diacon (2006) assevera que o Escritório Central da Comissão, situado no Rio de Janeiro, foi criado em 1910 com o intuito de sistematizar as informações acerca dos trabalhos da CLTEMTA e produzir relatórios e mapas a partir delas. Ao escritório cabia repassar esses mapas e relatórios aos órgãos governamentais interessados, entre eles, o Ministério da Guerra.

3 Para 'saber geográfico' sigo a definição de Sérgio Nunes (1999). Nesse texto, o autor problematiza a institucionalização do saber geográfico no Brasil. Seu argumento para a criação do termo é baseado em seu questionamento da importância, dada pela historiografia, à institucionalização acadêmica dessa área do conhecimento. Segundo Nunes, existiram outros âmbitos específicos nos quais o saber geográfico era desenvolvido, entre eles o mundo da formação e atuação militares; o autor propõe identificar e analisar os lugares em que esse conhecimento era produzido. Defendo, assim, que a comissão era um desses locais de produção do 'saber geográfico' por meio da atuação prática dos engenheiros militares.

${ }^{4}$ Sérgio Nunes (1999, p.8-9) afirma que "os engenheiros militares travavam um tipo de guerra, contudo esta não era contra os soldados inimigos, mas contra o abandono dos sertões, ao atraso que grassava nestas áreas, a batalha destes profissionais era contra a rudeza do meio geográfico, sua vitória estava na conquista da fronteira".

${ }^{5}$ Ver http://www.crl.edu/content/pindex.htm. 


\section{REFERÊNCIAS}

BIGIO, Elias dos Santos.

Cândido Rondon: a integração nacional. Rio de Janeiro: Contraponto, Petrobras. 2000.

CASER, Arthur Torres.

O medo do sertão: doenças e ocupação do território na Comissão de Linhas Telegráficas Estratégicas de Mato Grosso ao Amazonas (19071915). Dissertação (Mestrado) - Casa de Oswaldo Cruz/Fiocruz, Rio de Janeiro. 2009.

DIACON, Todd A.

Rondon: o marechal da floresta. São Paulo: Companhia das Letras. 2006.

LIMA, Nísia Trindade; SÁ, Dominichi Miranda de. Science and Territory in Brazil: The Brazilian army and the case of the Strategic Telegraph Commission of Mato Grosso to Amazonas (1907-1915). Historia y espacio, Cali, n.36, p.117-136. jan. 2011.

MACIEL, Laura Antunes.

A nação por um fio: caminhos, práticas e imagens da Comissão Rondon. São Paulo: Educ; Fapesp. 1998.
MENEZES, Maria Lúcia. P.

A noção geográfica de país na República Velha: Tratados e limites do Brasil. Scripta Nova, Barcelona, v.10, n.218. 2006. Disponível em: http://www.ub.es/geocrit/sn/sn-218-20.htm. Data de acesso: 14 out. 2010. 2006.

NUNES, Sérgio.

Engenheiros militares e saber geográfico: anotações para uma pesquisa. Trabalho apresentado no 1. Encontro Nacional de História do Pensamento Geográfico. Rio Claro. 1999.

RIBEIRO, Rafael Winter.

A invenção da diversidade: construção do Estado e diversificação territorial no Brasil (1889-1930). Tese (Doutorado) - Departamento de Geografia, Universidade Federal do Rio de Janeiro, Rio de Janeiro. 2005.

SÁ, Dominichi Miranda de; SÁ, Magali Romero; LIMA, Nísia Trindade.

Telégrafos e inventário do território no Brasil: as atividades científicas da Comissão Rondon (19071915). História, Ciências, Saúde - Manguinhos, Rio de Janeiro, v.15, n.3, p.779-810. 2008. 